\title{
High-Cycle Fatigue Properties at Cryogenic Temperatures in INCONEL 718 Nickel-based Superalloy*1
}

\author{
Yoshinori Ono*2, Tetsumi Yuri, Hideshi Sumiyoshi, Etsuo Takeuchi, \\ Saburo Matsuoka and Toshio Ogata
}

Materials Information Technology Station, National Institute for Materials Science (MITS/NIMS), Tsukuba 305-0047, Japan

High-cycle fatigue properties at $4 \mathrm{~K}, 77 \mathrm{~K}$ and $293 \mathrm{~K}$ were investigated in forged-INCONEL 718 nickel-based superalloy with a mean gamma $(\gamma)$ grain size of $25 \mu \mathrm{m}$. In the present material, plate-like delta phase precipitated at $\gamma$ grain boundaries and niobium (Nb)-enriched MC type carbides precipitated coarsely throughout the specimens. The $0.2 \%$ proof stress and the ultimate tensile strength of this alloy increased with decreasing temperature, without decreasing elongation or reduction of area. High-cycle fatigue strengths also increased with decreasing temperature although the fatigue limit at each temperature didn't appear even around $10^{7}$ cycles. Fatigue cracks initiated near the specimen surface and formed faceted structures around crack initiation sites. Fatigue cracks predominantly initiated from coarse Nb-enriched carbides and faceted structures mainly corresponded to these carbides. In lower stress amplitude tests, however, facets were formed through transgranular crack initiation and growth. These kinds of distinctive crack initiation behavior seem to lower the high-cycle fatigue strength below room temperature in the present material.

(Received November 17, 2003; Accepted December 22, 2003)

Keywords: nickel-based superalloy, fatigue properties, cryogenic temperatures, fractography, fatigue crack initiation, microstructure

\section{Introduction}

INCONEL 718 Ni-based superalloy (IN718) is a precipitation-strengthened material deriving from gamma prime $\left(\gamma^{\prime}: \mathrm{L}_{2}\right)$ and gamma double prime $\left(\gamma^{\prime \prime}: \mathrm{DO}_{22}\right)$. This alloy has been widely used in the gas turbine and related applications because of its good mechanical properties up to intermediate temperatures $(\sim 923 \mathrm{~K})$. Additionally, this alloy has been used for structural materials in aerospace industry, since this alloy has good weldability and good tensile properties in strength and ductility at cryogenic temperatures. ${ }^{1,2)}$

In recent years, the mechanical properties of structural materials used for Japanese-built launch vehicles have been studied with the aim of increasing their reliability. ${ }^{3,4)}$ The mechanical properties at cryogenic temperatures in IN718 need to be investigated since this alloy is used for, for example, liquid oxygen turbo-pumps and there is few data on high-cycle fatigue properties at cryogenic temperatures.

In this study, the high-cycle fatigue properties in forgedIN718 were investigated at $4 \mathrm{~K}, 77 \mathrm{~K}$ and $293 \mathrm{~K}$, and discussed in terms of how they correlate with aspects of crack initiation sites.

\section{Experimental Procedure}

The present material was hot-forged after $1473 \mathrm{~K}$ heating. After this forging process, the material was solution-treated at $1233 \mathrm{~K}$ for $3.6 \mathrm{ks}$, followed by water quenching. And then, a double aging treatment was conducted at $993 \mathrm{~K}$ and $898 \mathrm{~K}$ for $28.8 \mathrm{ks}$, respectively. The chemical composition of the present material is shown in Table 1. The microstructure of this alloy was observed by scanning electron microscopy (SEM) and energy dispersive X-ray spectroscopy (EDS).

Tensile tests and fatigue tests were carried out at $4 \mathrm{~K}, 77 \mathrm{~K}$, and $293 \mathrm{~K}$. Tensile tests were carried out using cylindrical specimens $6.25 \mathrm{~mm}$ in diameter and $35 \mathrm{~mm}$ in gauge length and at an initial strain rate of $2.4 \times 10^{-4} \mathrm{~s}^{-1}$. The fatigue test specimens were an hourglass-type with a minimum diameter of 4.5 or $6 \mathrm{~mm}$. Fatigue tests were performed using sinusoidal waveform loading and uniaxial tension-tension loading under stress ratio $(R)$ of 0.01 . Test frequencies of $4 \mathrm{~Hz}$ at $4 \mathrm{~K}$ and $10 \mathrm{~Hz}$ at $77 \mathrm{~K}$ and $293 \mathrm{~K}$ were chosen to minimize specimen temperature rise.

Fracture surfaces and crack initiation sites of failed specimens were studied by SEM and EDS.

\section{Results}

\subsection{Microstructure}

Figure 1 shows SEM backscattered electron images (a), (b) and a SEM secondary electron image (c) of the present material. The present material consists of equiaxed gamma $(\gamma)$ grains and the mean size of $\gamma$ grains is about $25 \mu \mathrm{m}$ (Fig. 1(a)). Plate-like delta-phase $\left(\delta: \mathrm{Ni}_{3} \mathrm{Nb}^{5)}\right)$ precipitated along grain boundaries (Fig. 1(b)) during the solution treatment at $1233 \mathrm{~K}$. On the other hand, coarse precipitates were found

Table 1 Chemical composition of the alloy used (mass\%).

\begin{tabular}{|c|c|c|c|c|c|c|c|c|c|c|c|c|c|c|}
\hline $\mathrm{C}$ & $\mathrm{Si}$ & $\mathrm{Mn}$ & $\mathrm{P}$ & $\mathrm{S}$ & $\mathrm{Cu}$ & $\mathrm{Ni}$ & $\mathrm{Cr}$ & Mo & $\mathrm{Co}$ & $\mathrm{Al}$ & $\mathrm{Ti}$ & B & $\mathrm{Nb}$ & $\mathrm{Fe}$ \\
\hline 0.04 & 0.08 & 0.06 & 0.003 & 0.001 & 0.02 & 53.05 & 18.03 & 3.08 & 0.09 & 0.52 & 0.96 & 0.004 & 4.95 & bal. \\
\hline
\end{tabular}

\footnotetext{
${ }^{* 1}$ This Paper was Presented at the Autumn Meeting of the Japan Institute of

Metals, held in Sapporo, on October 13, 2003

${ }^{* 2}$ Researcher, Cryogenic Materials Group
} 

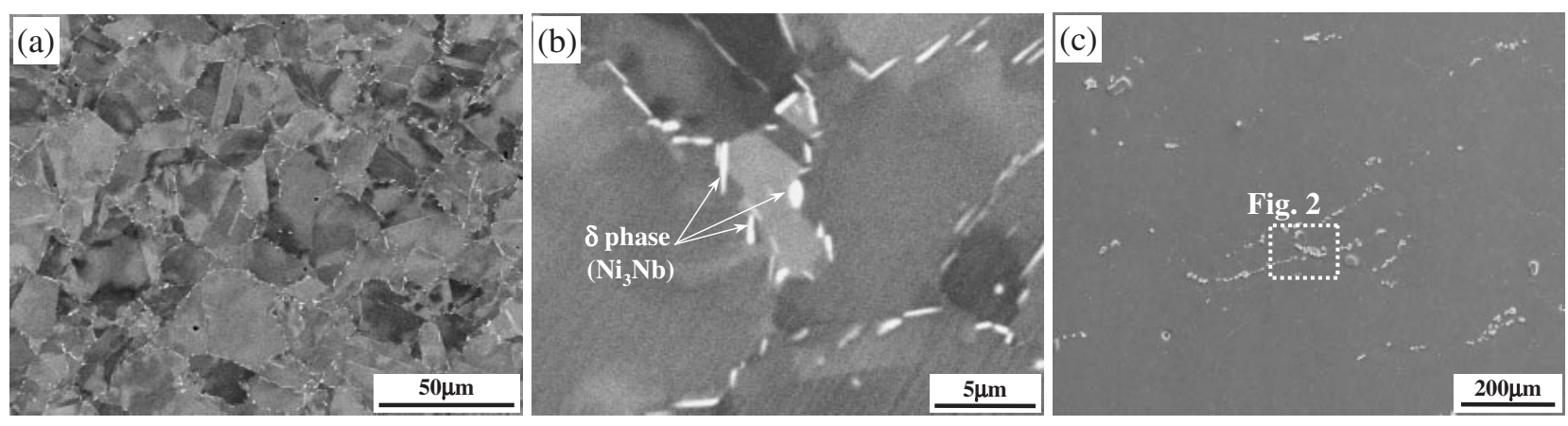

Fig. 1 SEM backscattered electron images showing a typical microstructure (a), $\delta$ phase precipitated on grain boundaries (b), respectively. SEM secondary electron image showing distribution of coarse precipitates (c).
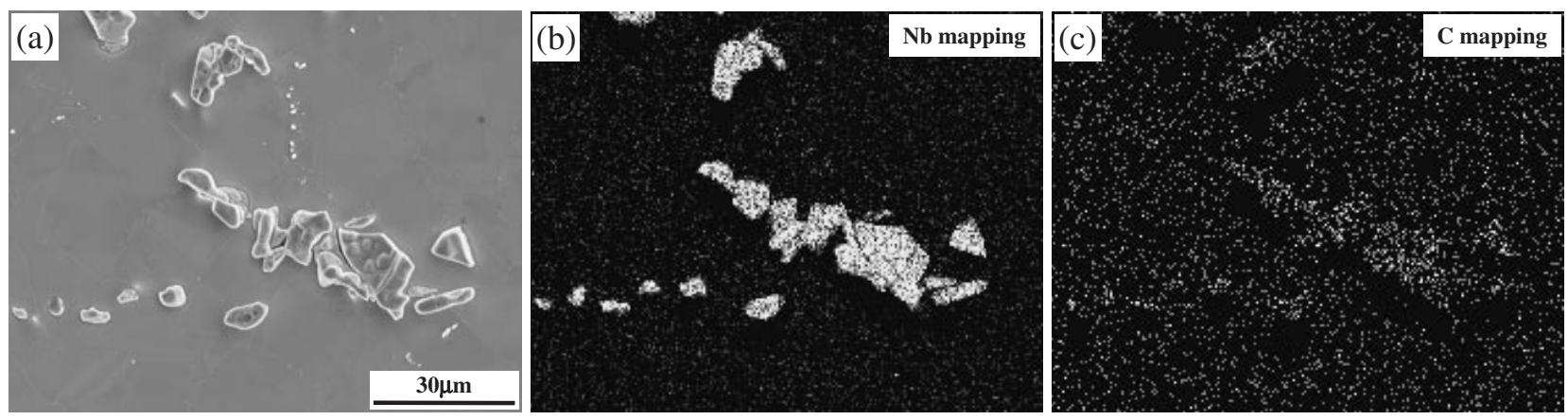

Fig. 2 SEM secondary electron image showing a magnified image of the square area in Fig. 1(c) (a), and niobium (b) and carbon (c) mapping by EDS, respectively.

throughout the specimens, as shown in Fig. 1(c). Figure 2 shows the magnified image of them and results of the EDS mapping. Each size of coarse precipitates is around 10-30 $\mu \mathrm{m}$ (Fig. 2(a)). However, they tend to exist aggregately and size of one aggregating area is over $100 \mu \mathrm{m}$ in longitudinal direction. EDS revealed that these coarse precipitates were mainly $\mathrm{Nb}$-enriched carbides (MC-type carbides) ${ }^{6}$ (Figs. 2(b), (c)).

\subsection{Tensile properties and Fatigue properties}

Tensile properties in the present material are summarized in Table 2 . The $0.2 \%$ proof stress and the ultimate tensile strength increased with decreasing temperature. However, the total elongation and the reduction of area were almost the same below $293 \mathrm{~K}$ and didn't decrease at cryogenic temperatures even with the increase in the $0.2 \%$ proof stress and the ultimate tensile strength. This result represents that IN718 has good tensile strength and ductility even at cryogenic temperatures. Figure 3 shows S-N diagrams for the present material. The fatigue strength increased with decreasing temperature similarly to the tensile strengths, although the fatigue limits didn't appear even around $10^{7}$ cycles.

Table 2 Tensile properties in INCONEL 718 superalloy used in this study.

\begin{tabular}{lrrr}
\hline \multicolumn{1}{c}{ Tensile properties } & \multicolumn{1}{c}{$4 \mathrm{~K}$} & $77 \mathrm{~K}$ & $293 \mathrm{~K}$ \\
\hline $0.2 \%$ proof stress (MPa) & 1414 & 1327 & 1174 \\
Ultimate tensile strength (MPa) & 1822 & 1640 & 1369 \\
Total elongation (\%) & 15.3 & 12.5 & 10.6 \\
Reduction of area (\%) & 14.2 & 13.1 & 14.6 \\
\hline
\end{tabular}

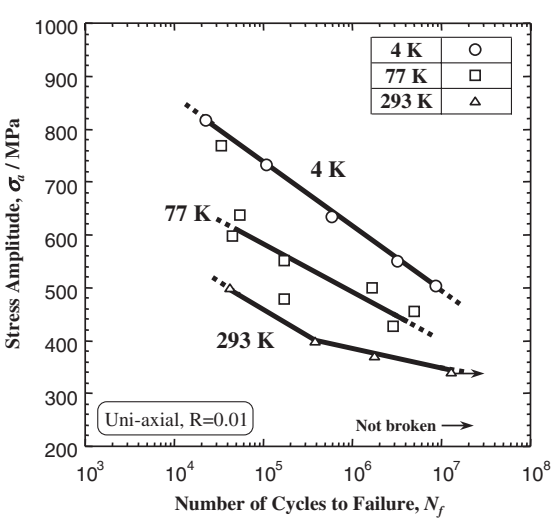

Fig. 3 S-N diagrams at $4 \mathrm{~K}, 77 \mathrm{~K}$ and $293 \mathrm{~K}$ for INCONEL 718 alloy used in this study.

\subsection{Fractography}

Figure 4 represents typical SEM micrographs showing the fracture surfaces of the specimens fatigue-tested at $77 \mathrm{~K}$. Basically, the aspects of the fracture surfaces were almost the same in the specimens failed at $4 \mathrm{~K}, 77 \mathrm{~K}$ and $293 \mathrm{~K}$. Fatigue cracks initiated near the specimen surface (Figs. 4(a), (b)), and faceted structures (we abbreviate each faceted structure to 'facet') were observed around the crack initiation site (Fig. 4(b)). As a result of EDS mapping, the arrowed facet in Fig. 4(b), which seems to be the crack initiation site, and some other facets being around the crack initiation site were found to be $\mathrm{Nb}$-enriched areas (Fig. 4(c)). This result reveals that the fatigue cracks predominantly initiated from $\mathrm{Nb}$-enriched carbides located near the specimen surface. In other precipitation-strengthened superalloys, similar results were reported in low-cycle or high-cycle fatigue tests at room 

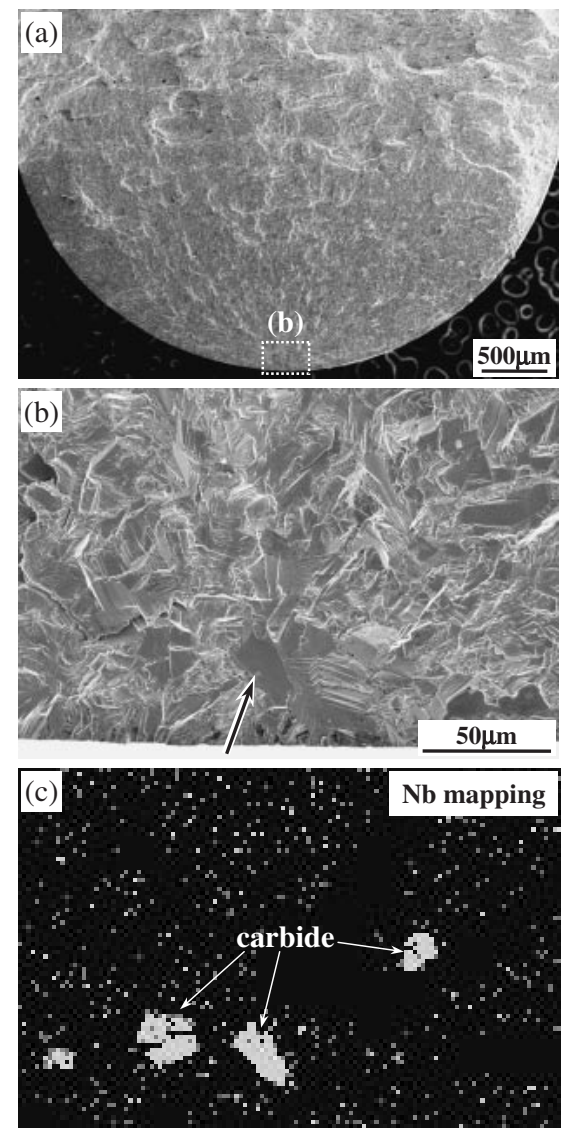

Fig. 4 SEM micrographs showing fracture surface (a), the vicinity of fatigue crack initiation site (b) and niobium mapping by EDS for the same area shown in (b) (c). The specimen was fatigue-tested at $77 \mathrm{~K}$; $\sigma_{\mathrm{a}}=427 \mathrm{MPa}, N_{\mathrm{f}}=2,883,070$.

temperature ${ }^{7,8)}$ and at $700 \mathrm{~K} .{ }^{9)}$ However, the aspects of the crack initiation sites were different in lower stress amplitude tests. Figure 5 shows secondary electron images and $\mathrm{Nb}$ mappings by EDS around the fatigue crack initiation sites of the specimens fatigue-tested at $4 \mathrm{~K}$. In higher stress amplitude tests, the facets, which seemed to be crack initiation sites or were observed around crack initiation sites, corresponded to the Nb-enriched carbides (Figs. 5(a), (b), (c), (d)). However, in lower stress amplitude tests, there was no Nbenriched area identified as crack initiation site (Fig. 5(f)) and the size of each facet was larger than in the higher stress amplitude tests (Fig. 5(e)).

Figure 6 represents the microstructure under the crack initiation sites of the specimen fatigue-tested at $4 \mathrm{~K}$. The fracture surface of this specimen is shown in Fig. 5(e). Fig. 6(a) reveals that, in the lower stress amplitude tests, the facets were formed through transgranular cracking. These observations suggest that the crack initiation behavior changes depending on the mean stress. In Fig. 6(b), cracks penetrate $\mathrm{Nb}$-enriched carbides and this observation infers that the cracking in $\mathrm{Nb}$-enriched carbide cause the fatigue failure in case the carbide is identified as crack initiation site (Fig. 4).

\section{Discussion}

It is known that there is a good correlation between fatigue limit $\left(\sigma_{\mathrm{w}}\right.$ : fatigue strength at $10^{7}$ cycles $)$ and ultimate tensile
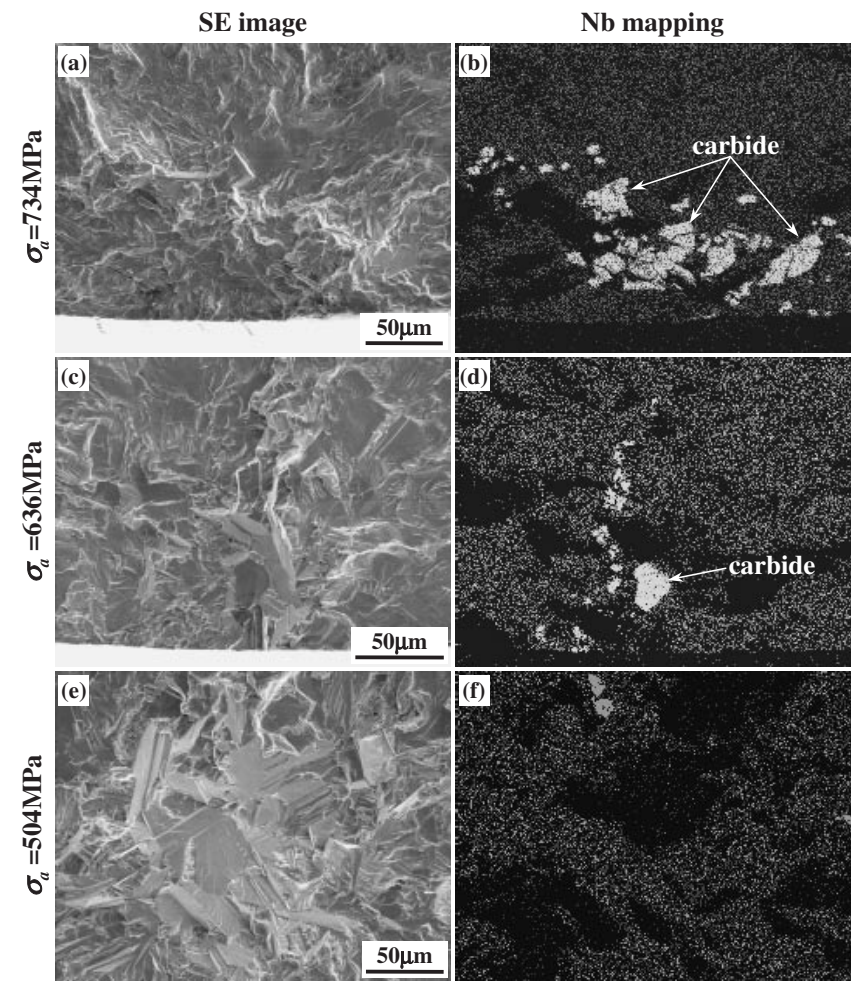

Fig. 5 SEM secondary electron images showing the fatigue crack initiation sites (a), (c), (e), and niobium mapping by EDS (b), (d), (f), respectively. These specimens were fatigue-tested at $4 \mathrm{~K}$.
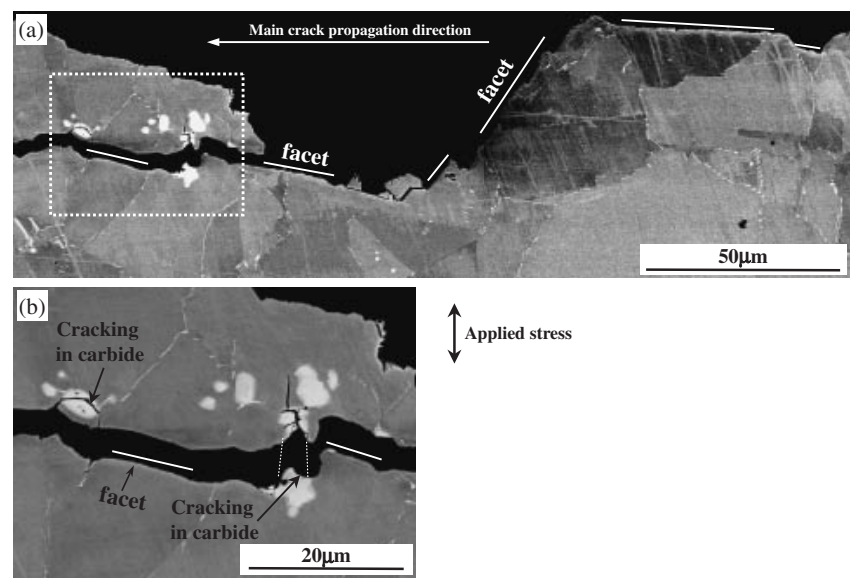

Fig. 6 SEM backscattered electron images showing the microstructure under the crack initiation site in the specimen fatigue-tested at $4 \mathrm{~K}$; $\sigma_{\mathrm{a}}=504 \mathrm{MPa}, N_{\mathrm{f}}=8452770$. Photograph (b) is the magnified image of the square area in photograph (a).

strength $\left(\sigma_{\mathrm{u}}\right)$ in case where the fatigue crack initiates at the specimen surface. This correlation has been characterized by the empirical equation $\sigma_{\mathrm{w}}=C \sigma_{\mathrm{u}}{ }^{10)} \mathrm{C}$ is the constant. At room temperature, $C$ is about 0.52 under $R=-1$ on various tempered martensitic steels and aluminum alloys, ${ }^{11)}$ and 0.42 under $R=0$ on various tempered martensitic steels. ${ }^{12)}$ Reflecting this relationship for fatigue limit, the relationship between the stress amplitude to the ultimate tensile strength $\left(\sigma_{\mathrm{a}} / \sigma_{\mathrm{u}}\right)$ and number of cycles to failure $\left(N_{\mathrm{f}}\right)$ is expressed as an unique curve for the materials in which the fatigue crack initiates at the specimen surface. ${ }^{11)}$ Figure 7 shows the 


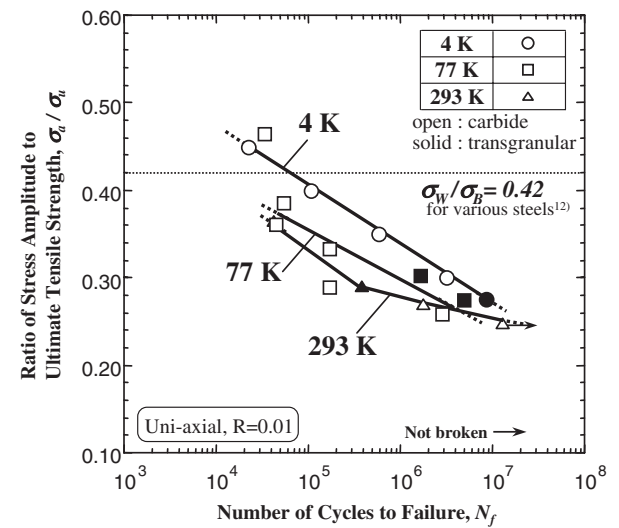

Fig. 7 Relationship between ratio of stress amplitude $\left(\sigma_{\mathrm{a}}\right)$ to ultimate tensile strength $\left(\sigma_{\mathrm{u}}\right)$ and number of cycles to failure.

relationship between ratio of the stress amplitude to the ultimate tensile strength $\left(\sigma_{\mathrm{a}} / \sigma_{\mathrm{u}}\right)$ and number of cycles to failure $\left(N_{\mathrm{f}}\right)$. In the present material, the $\sigma_{\mathrm{a}} / \sigma_{\mathrm{u}}$ value at $10^{7}$ cycles is estimated about 0.25 irrespective of test temperatures and is fairly lower than those of steels $(C=0.42)$, in which fatigue crack initiates from the specimen surface without forming facets as observed in the present material. This result suggests that carbide or transgranular crack initiation as shown in Figs. 4 and 5 results in lowering the fatigue strength in longer-life region in the present material. In the high-strength steels whose $\sigma_{\mathrm{u}}$ exceeds $1200 \mathrm{MPa}$, fatigue cracks originate mainly from inclusions such as $\mathrm{Al}_{2} \mathrm{O}_{3}$ or $\mathrm{CaO}$ in the high-cycle region, and the ratio of $\sigma_{\mathrm{w}}$ values (fatigue strengths at $10^{8}$ cycles) to ultimate tensile strength is clearly lower than steels in which fatigue cracks initiate at the specimen surface. ${ }^{13)}$ Additionally, it was reported that the transglanular crack initiation caused by heterogeneous deformation is related with low fatigue strength in longer-life region in other Ni-based superalloys ${ }^{14)}$ or titanium alloy. ${ }^{4)}$

It is difficult to elucidate the mechanism on a transition in crack initiation behavior in the present material in this paper. However, reflecting the results obtained in this study, one of important factors for improving the high-cycle fatigue properties at cryogenic temperatures is to control the size or distribution of $\mathrm{Nb}$-enriched carbides. In other words, refining the carbides or reducing the volume fraction of carbides leads to the improvement of high-cycle fatigue properties. One more important factor seems to refine $\gamma$ grains for improving high-cycle fatigue properties at low stress amplitude. This is because fine grains are effective resistance for short fatigue crack propagation, in which facets are formed. ${ }^{15)}$

\section{Conclusions}

High-Cycle fatigue properties at cryogenic temperatures and fracture surfaces of the failed specimens were investigated in forged-INCONEL718, which is used for the Japanese-built launch vehicles. The results obtained are as follows:

(1) The $0.2 \%$ proof stress and the ultimate tensile strength of this alloy increased with decreasing temperature, without decreasing elongation or reduction of area. At cryogenic temperatures, fatigue strengths in longer-life region increased in response to increments in tensile strength. However, the fatigue limits don't appear even around $10^{7}$ cycles at each temperature.

(2) Fatigue cracks initiated near the specimen surface. Fatigue cracks predominantly initiated from coarse $\mathrm{Nb}$ enriched carbides. However, the transgranular crack initiation occurs in lower stress amplitude tests. These kinds of distinctive crack initiation behavior seem to lower the high-cycle fatigue strength below room temperature in the present material.

\section{REFERENCES}

1) K. Hasegawa, K. Ando, S. Kitade, M. Sakamoto, Y. Fukushima and K. Okita: Trans. Jpn. Soc. Mech. Eng. A61 (1995) 1707-1712.

2) S. Hamai, K. Satoh, Y. Sugiura, H. Manako and Y. Fukushima: J. the Japan Society for heat treatment 40 (2000) 232-237.

3) T. Yuri, Y. Ono and T. Ogata: J. Japan Inst. Metals 66 (2002) 12871292.

4) Y. Ono, T. Yuri, H. Sumiyoshi, S. Matsuoka and T. Ogata: Mater. Trans. 44 (2003) 1702-1705.

5) P. E. Mosser, G. Leconte, J. Leray, A. Lasalmonie and Y. Honnorat: Superalloy 718-Metallurgy and Applications, ed. E. A. Loria, (The Minerals, Metals \& Materials Society, 1989) pp. 179-188.

6) C. Chen, R. G. Thompson and D. W. Davis: Superalloys 718, 625 and Various Derivatives, ed. E. A. Loria, (The Minerals, Metals \& Materials Society, 1991) pp. 81-96.

7) M. Gell and G. R. Leverant: Trans. Metall. Soc. AIME 242 (1968) 1869-1879.

8) T. Denda, P. L. Bretz and J. K. Tien: Metall. Trans. 23A (1992) 519526.

9) C. Ruiz, A. Obabueki and K. Gillespie: Superalloys 1992, ed. S. D. Antolovich, R. W. Stusrud, R. A. MacKay, D. L. Anton, T. Khan, R. D. Kissinger and D. L. Klarstrom, (The Minerals, Metals \& Materials Society, 1992) pp. 33-42.

10) Y. Murakami: Metal fatigue, effects of small defects and nonmetallic inclusions, (Oxford: Elsevier Science Ltd, 2002).

11) S. Matsuoka, N. Nagashima and S. Nishijima: Mater. Strength Data Sheet Technical Document No. 17, Tokyo: National Research Institute for Metals, (1997). (in Japanese)

12) S. Nishijima et al.: Mater. Strength Data Sheet Technical Document No. 5, Tokyo: National Research Institute for Metals, (1989). (in Japanese)

13) T. Abe, Y. Furuya and S. Matsuoka: Trans. Jpn. Soc. Mech. Eng. A67 (2001) 1988-1995. (in Japanese)

14) M. Gell and G. R. Leverant: Ordered alloys, ed. B. H. Kear, C. T. Sims, N. S. Stoloff and J. H. Westbrook, (Claitor's Publishing Division, 1970) pp. 505-523.

15) C. W. Brown, J. E. King and M. A. Hicks: Met. Sci. 18 (1984) 374-380. 